\title{
Comparison of on-farm progeny performances from local and imported boar semen used in the South African pig industry
}

\author{
D.A. Krüger ${ }^{1}$, E. van Marle-Koster ${ }^{1 \#}$ \& H.E. Theron ${ }^{1}$ \\ ${ }^{1}$ Department of Animal and Wildlife Sciences, University of Pretoria, Private Bag X20, Hatfield, 0028, South Africa
}

(Received 24 April 2017; Accepted 9 August 2017; First published online 11 September 2017)

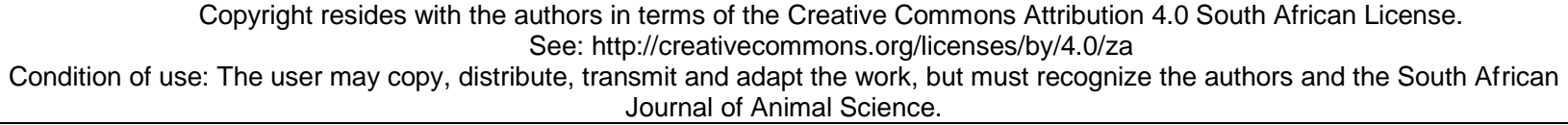

\begin{abstract}
The widespread use of artificial insemination in the pig industry has provided breeders with access to genetic material from superior boars from around the world. Selection of parent stock is based on estimated breeding values (EBVs), which are regularly computed in all countries performing genetic evaluations. The purpose of this study was to evaluate the value of foreign sires in the South African (SA) pig industry by comparing the on-farm performances of progeny for average daily gain (ADG), feed conversion ratio (FCR) and back fat thickness (BF) from progeny sired by USA and Canadian born sires to the performance of progeny from local sires and to progeny with paternal USA grandsires (F1-US sires). The breeds analysed comprised of Duroc, Landrace and Large White pigs. Males outperformed females for all traits measured $(P$ $<0.0001)$. Large differences $(P<0.0001)$ were observed between on-farm performances which had similar climatic regions for all traits except Duroc BF $(P<0.05)$. Farm differences were consequently attributed to management rather than environmental influences. The effect of country was significant $(P<0.05)$ in all the models tested with the USA-sired progeny having the best overall performance. However, as measured by a stepwise $R^{2}$, country remained the smallest contributor to variation across all models (except $B F$ in Landrace), with farm, sex and year-season contributing larger portions to the variation observed in the onfarm performances of progeny. These results indicate that most of the variation observed could be attributed to differences in farm as explained by management, rather than superiority of the imported boar semen.
\end{abstract}

Keywords: Average daily gain, back fat thickness, feed conversion ratio, on-farm performance

\# Corresponding author: este.vanmarle-koster@up.ac.za

\section{Introduction}

The South African pig industry is small compared to other livestock sectors, such as cattle or sheep. Despite the small size, pig breeders have been using available breeding tools, including animal and pedigree recording, on farm growth testing and estimated breeding values to ensure genetic improvement in their herds. The breeding sector consists of only nine independent pig stud breeders, jointly contributing $27 \%$ to South Africa's pig breeding stock (Streicher, 2013). Of the nine stud breeders, six breeders formed the breeders company Alliance Genetics South Africa (AGSA) in 2011. The remaining 73\% of the breeding stock in South Africa is supplied by two international breeding companies, TOPIGS and PIC (Buchanan \& Stalder, 2011; Kirsten et al., 2009).

South Africa has followed the global trend of using artificial insemination in the pig industry, with an estimated 70 to $75 \%$ of matings done through artificial insemination (Al) (Gerrits et al., 2005; Visser et al., 2014). There are five recognised Al stations across the country with a combined standing capacity of 290 boars and a potential maximum output of 10000 doses per week (Department of Agriculture Forestry and Fisheries, 2011). With the use of artificial insemination comes several advantages, one of the most significant being the availability of semen from superior boars across the global community, allowing breeders to choose parents superior to their own breeding stock (Whittemore, 2006a). Due to stringent import requirements, pig semen imports by the South African stud breeders have been largely restricted to Canada and the USA. Following the outbreak of Porcine Epidemic Diarrhoea virus (PEDv), all pig semen imports have been halted except for individual trade partners that have sufficient health measures in place to prevent the spread of PEDv (Department of Agriculture Forestry and Fisheries, 2014; Visser, 2015).

South African pig breeders focus on five traits that are considered to have the highest economic importance; two fertility traits (number born alive (NBA) and 21 day litter weight (21DLWT)) and three growth 
and production traits (average daily gain (ADG), feed conversion ratio (FCR) and back fat thickness (BF)). The production traits are measured during the on-farm growth tests, occasionally including individual feed intake to calculate FCR, which starts between 20 and $40 \mathrm{~kg}$ and ends between 85 and $100 \mathrm{~kg}$. At the end of the growth test, the starting and end age and weight are used to calculate the average daily gain, and $\mathrm{P}_{2}$ back fat thickness is measured ultrasonically (Visser, 2015). The five traits are combined to form an aggregate, known as the Rand value index (RVI) (Visser \& Hofmeyer, 2014), and are also used to generate EBVs for both local Al sires and imported pig semen used in South Africa. These traits are also considered in selection programs of pig breeders in the USA and Canada. Additionally, traits such as number weaned, lean yield (NSR, 2013; Robinson \& Buhr, 2005), loin eye area, piglet perinatal survivability, farrowing interval and number of functional teats are also used in their selection programs (CCSI, 2012; Chesnais \& Sullivan, 2002).

South African pig breeders select boars for importation of semen with superior performance in fertility and growth traits based on performance data and/or EBV values from their country of origin, with the aim to enhance genetic progress. Due to the structure of the pig breeding industry and a relatively short generation interval, it is of paramount importance for SA breeders to monitor the effect of foreign sires used in the local industry. In this study, the value of foreign sires used in the South African pig industry was evaluated by comparing the on-farm performances of progeny produced from local versus imported boar semen.

\section{Materials and Methods}

Pedigree and performance data for progeny sired by local and foreign boar semen was provided by SA Stud Book (118 Henry Street, Westdene, Bloemfontein, South Africa) with consent from the South African Pork Producers Organisation (SAPPO) and the Ethics Committee of the University of Pretoria for use of the data. The data received included a list of imported boars used over the last 14 years, raw on-farm performance data for all their progeny born in South Africa, all litter data and a pedigree file linking progeny, sires and dams. A total of 3152 sires, of which 159 were Canadian, 73 from the USA and 2920 South African, had a combined total of 87158 progeny, including Chester White, Duroc, Landrace, L06 and L65 lines, Large White and Pietrain.

Data editing required limiting the data to only Duroc, Landrace and Large White breeds as they were the only boars imported from both Canada and the USA. The Chester White boars were excluded due to insufficient number of records available for the analyses. The data set with the boar information was further filtered to only include those that had at least one litter in South Africa and available progeny performances. The South African (SA) boars were divided into two groups, SA boars and first generation SA boars that were born in SA and sired by USA boars, termed F1-US. All progeny were linked to their sire and their sire's country of origin (CA, F1-US, USA and SA). The number of boars were reduced from 3152 boars used in South Africa, to 3010 boars with at least one recorded litter (Table 1). A filter was applied to restrict the progeny to only those from both local- and foreign-sires, born on the same farm during the same summer/winter period, where the winter period is from March to August and the summer period from September to February of the following year. The number of progeny was reduced to 27334 from seven farms (A, B, C, D, E, F and G). The Large White had the most progeny performance data available, followed by the Duroc and the Landrace.

Table 1 Number of Al boars with litters in South Africa since 2000

\begin{tabular}{lcccc}
\hline \multirow{2}{*}{ Breed } & \multicolumn{3}{c}{ Country of origin } & \multirow{2}{*}{ Breed Total } \\
\cline { 2 - 4 } & Canada & USA & South Africa & \\
\hline Duroc & 5 & 23 & 575 & 603 \\
Landrace & 10 & 13 & 782 & 805 \\
Large White & 30 & 33 & 1539 & 1602 \\
Country Total & 45 & 69 & 2896 & 3010 \\
\hline
\end{tabular}

On-farm progeny performances were compared on the same farm and for the same year-season to reduce environmental variation. Traits that were evaluated included on-farm performances for ADG, FCR and BF. Across all three breeds, FCR was not recorded as frequently as ADG and BF, with no FCR records available for any of the 288 Canadian-sired progeny. 
All the statistical analyses were performed in SAS Enterprise Guide 4.3 (SAS, 2014). Analyses were performed separately for each of the three breeds. Descriptive statistics were calculated separately for each sex and farm-country combination for each of the three performance traits; ADG (g) during the test period, $\mathrm{FCR}\left(\mathrm{kg}\right.$ fed $/ \mathrm{kg}$ gain) during the test period and the $\mathrm{P}_{2} \mathrm{BF}(\mathrm{mm})$ at the end of the test period.

Statistical analyses comparing the influence of known variables on the different traits for each breed was accomplished through the general linear method (GLM) procedure in SAS Enterprise Guide 4.3 (SAS, 2014). A linear model analysis of variance (ANOVA) was conducted separately for each of the traits, for each breed. The linear model used for the analyses is described as follows:

$$
y_{i j}=\mu+\beta_{i}+e_{i j}
$$

\begin{tabular}{|c|c|c|}
\hline Where: $y_{i j}$ & $=$ & performance record $j$ for fixed effect $i$ \\
\hline$\mu$ & $=$ & grand population mean \\
\hline$\beta_{i}$ & $=$ & $i^{\text {th }}$ fixed effect contributing to variation \\
\hline$e_{i j}$ & $=$ & dom error for performance record $j$ for the $i^{t h}$ effect \\
\hline
\end{tabular}

The fixed effects tested across all analyses included country, farm, sex, year-season, sire, dam, dam parity and dam age. Additionally, starting weight and end age were tested in the ADG models, BF and end age were tested in the FCR models, while ADG, end weight and end age were tested in the BF models. Difference between the least square means (LSMean) were determined by the Bonferroni test for country, farm and sex. Differences were considered statistically significant at $P<0.05$, and highly significant at $P$ $<0.0001$. In addition, a step-wise $R^{2}$ was recorded for each effect in the ANOVAs to give an indication of its contribution to the overall variation.

\section{Results}

The descriptive statistics for on-farm performances for each breed and country combination for ADG, FCR and BF are shown in Table 2. The USA-sired Duroc progeny had the highest average ADG (940 g/d) and BF $(10.17 \mathrm{~mm})$ performances, while the SA-sired Duroc progeny had the lowest average FCR $(2.13 \mathrm{~kg}$ fed $/ \mathrm{kg}$ gain). The Canadian-sired Duroc progeny had the lowest BF performances $(9.57 \mathrm{~mm})$. The F1-US sired Landrace progeny had the highest average ADG $(890.45 \mathrm{~g} / \mathrm{d})$, and the lowest average FCR $(2.05 \mathrm{~kg}$ fed $/ \mathrm{kg}$ gain) and BF $(10.45 \mathrm{~mm})$ performances. The USA-sired Large White progeny had the highest average ADG (910.12 g/d), as well as the lowest average FCR (2.06 kg fed/kg gain) and BF (9.42 mm) onfarm performances.

The significant variables tested for each of the three traits, per breed, are shown in Table 3 . The influence of sire, dam, dam parity and dam age were not significant in any of the models, while the influence of farm, country, sex and the year-season interaction were significant $(P<0.05)$. The influence of starting weight was only found to be significant $(P<0.05)$ in Duroc and Large White ADG, while end weight was significant in the BF performance of all breeds. Except for BF in the Duroc and Landrace, end age had a significant influence on all the traits. Lastly, BF had a significant influence on the FCR of all three breeds, while ADG had a significant influence on BF in all breeds.

Results for the stepwise R-square contributions are summarised in Table 4 for the four main significant effects; country, farm, sex and year-season. On average, country contributed the lowest variation and the least amount of variation in all the models except for $\mathrm{BF}$ in the Landrace. Stepwise R-square for country never exceeded $2.15 \%$, with its lowest contribution to FCR in the Duroc $(0.20 \%)$. Farm contributed a moderate amount of variation to the on-farm performances, ranging from $1.92 \%$ to $18.96 \%$, with an average contribution of $8.08 \%$. Sex and year-season both contributed large portions of variation, with an average contribution of $12.36 \%$ and $9.84 \%$, respectively. For ADG, end age was found to have the largest effect, contributing $30.34 \%, 28.14 \%$, and $24.14 \%$ of the variation in the Duroc, Landrace, and Large White, respectively.

ANOVA results for the Duroc performances are summarised in Table 5. A difference $(P<0.05)$ was found between country for performances in ADG, FCR and BF. Canadian sired progeny performed statistically no difference to the other progeny in both ADG and BF. The ADG and FCR performances of US sired progeny were superior $(P<0.05)$ to both F1-US and SA sired progeny performances, while SA sired progeny's BF performances were higher $(P<0.05)$ in comparison to both $\mathrm{F} 1$-US and US sired progeny's performances. Farm performances were shown to be different for ADG, FCR $(P<0.0001)$ and BF $(P<0.05)$. Marked differences $(P<0.05)$ were found in performances of ADG and FCR on the different farms. 
Table 2 Descriptive statistics for on-farm performances of progeny for each breed and country combination for average daily gain, feed conversion ratio and back fat thickness

\begin{tabular}{|c|c|c|c|c|c|c|c|c|c|c|c|}
\hline \multirow{2}{*}{ Breed } & \multirow{2}{*}{ Sire country } & \multirow{2}{*}{$\begin{array}{c}\text { Mean age (days) } \\
\text { to } 90 \mathrm{~kg}\end{array}$} & \multicolumn{3}{|c|}{$A D G$} & \multicolumn{3}{|c|}{ FCR } & \multicolumn{3}{|c|}{$\mathrm{BF}$} \\
\hline & & & $\mathrm{N}$ & Mean & SD & $\mathrm{N}$ & Mean & SD & $\mathrm{N}$ & Mean & SD \\
\hline \multirow{4}{*}{ Duroc } & $\mathrm{CA}$ & 142.7 & 79 & 933.37 & 90.49 & & & & 79 & 9.57 & 1.38 \\
\hline & F1-US & 141.2 & 1895 & 921.97 & 112.99 & 232 & 2.15 & 0.30 & 1895 & 9.58 & 1.52 \\
\hline & USA & 140.7 & 339 & 940.79 & 118.31 & 105 & 2.16 & 0.29 & 339 & 10.17 & 1.44 \\
\hline & SA & 138.7 & 6576 & 933.51 & 107.14 & 618 & 2.13 & 0.29 & 6576 & 9.97 & 1.85 \\
\hline \multirow[t]{4}{*}{ Landrace } & $\mathrm{CA}$ & 142.4 & 119 & 860.17 & 87.24 & & & & 119 & 10.96 & 1.54 \\
\hline & F1-US & 142.5 & 1304 & 890.45 & 120.84 & 174 & 2.05 & 0.25 & 1304 & 10.45 & 1.72 \\
\hline & USA & 142.4 & 193 & 878.12 & 128.77 & 51 & 2.11 & 0.27 & 193 & 10.88 & 1.88 \\
\hline & SA & 142.7 & 5690 & 883.47 & 117.92 & 1064 & 2.17 & 0.3 & 5690 & 11.16 & 2.09 \\
\hline \multirow{3}{*}{ Large White } & $\mathrm{CA}$ & 141.2 & 90 & 876.82 & 94.90 & & & & 90 & 10.56 & 1.34 \\
\hline & USA & 141.3 & 521 & 910.12 & 145.28 & 125 & 2.06 & 0.24 & 521 & 9.42 & 1.72 \\
\hline & SA & 145.1 & 10528 & 893.30 & 110.78 & 722 & 2.16 & 0.31 & 10528 & 9.77 & 2.11 \\
\hline
\end{tabular}

$\mathrm{N}=$ number of records, $\mathrm{SD}$ = standard deviation, $\mathrm{ADG}=$ average daily gain $(\mathrm{g}), \mathrm{FCR}=$ feed conversion ratio $(\mathrm{kg}$ feed $/ \mathrm{kg}$ gain), BF = back fat thickness $(\mathrm{mm}), \mathrm{CA}=$ progeny sired by Canadian boars, F1-US = SA sired progeny with a USA grandsire, USA = progeny sired by USA boars, SA = progeny sired by South African boars

Table 3 Statistically significant $(P<0.05)$ variables and model R-square for each of the nine ANOVAs

\begin{tabular}{|c|c|c|c|}
\hline Trait & Breed & Significant effects & R-sq \\
\hline \multirow[t]{3}{*}{ ADG } & Duroc & country, farm, sex, year-season, start weight, end age, end age ${ }^{2}$ & 0.5880 \\
\hline & Landrace & country, farm, sex, year-season, end age, end age ${ }^{2}$ & 0.6113 \\
\hline & Large White & country, farm, sex, year-season, start weight, end age, end age ${ }^{2}$ & 0.5308 \\
\hline \multirow[t]{3}{*}{ FCR } & Duroc & country, farm, sex, year-season, BF, end age & 0.5347 \\
\hline & Landrace & country, farm, sex, year-season, BF, end age, end age ${ }^{2}$ & 0.5512 \\
\hline & Large White & country, farm, sex, year-season, BF, end age & 0.5508 \\
\hline \multirow[t]{3}{*}{$\mathrm{BF}$} & Duroc & country, farm, sex, year-season, ADG, end weight & 0.3601 \\
\hline & Landrace & country, farm, sex, year-season, ADG, end weight, & 0.1713 \\
\hline & Large White & country, farm, sex, year-season, ADG, end weight, end age, end age ${ }^{2}$ & 0.2836 \\
\hline
\end{tabular}

$\mathrm{ADG}=$ average daily gain $(\mathrm{g}), \mathrm{FCR}=$ feed conversion ratio $(\mathrm{kg}$ feed $/ \mathrm{kg}$ gain), $\mathrm{BF}=$ back fat thickness $(\mathrm{mm}), \mathrm{R}-\mathrm{sq}=$ coefficient of determination 
Table 4 Stepwise R-sq contributions for the four main effects in the nine ANOVA models

\begin{tabular}{|c|c|c|c|c|c|}
\hline Trait & Breed & Country & Farm & Sex & Year-Season \\
\hline \multirow[t]{3}{*}{ ADG } & Duroc & $0.22 \%{ }^{*}$ & $1.92 \%{ }^{* *}$ & $13.80 \%{ }^{\star *}$ & $9.99 \%{ }^{* *}$ \\
\hline & Landrace & $0.13 \%{ }^{* *}$ & $8.69 \%{ }^{* *}$ & $18.07 \%{ }^{* *}$ & $4.14 \%{ }^{* *}$ \\
\hline & Large White & $0.12 \%{ }^{\star \star}$ & $8.39 \%{ }^{* *}$ & $7.96 \%{ }^{*}$ & $10.32 \%{ }^{* *}$ \\
\hline \multirow[t]{3}{*}{ FCR } & Duroc & $0.20 \%{ }^{*}$ & $18.96 \%{ }^{* *}$ & $15.37 \%{ }^{* \star}$ & $6.18 \%{ }^{* *}$ \\
\hline & Landrace & $2.15 \%{ }^{*}$ & $9.39 \%{ }^{* *}$ & $21.35 \%{ }^{* *}$ & $9.35 \%{ }^{* *}$ \\
\hline & Large White & $1.27 \%{ }^{*}$ & $10.82 \%{ }^{* *}$ & $19.14 \%{ }^{* \star}$ & $12.11 \%{ }^{* *}$ \\
\hline \multirow[t]{3}{*}{$\mathrm{BF}$} & Duroc & $0.91 \%{ }^{*}$ & $0.82 \%{ }^{*}$ & $5.81 \%{ }^{* *}$ & $24.88 \%{ }^{* \star}$ \\
\hline & Landrace & $1.79 \%{ }^{* *}$ & $5.34 \%{ }^{* *}$ & $1.30 \%{ }^{* *}$ & $6.07 \%{ }^{* *}$ \\
\hline & Large White & $0.25 \%{ }^{\star \star}$ & $8.42 \%{ }^{* *}$ & $8.48 \%{ }^{* *}$ & $5.52 \%{ }^{* \star}$ \\
\hline
\end{tabular}

indicates the effect was significant $(P<0.05)$

indicates the effect was highly significant $(P<0.0001)$

Table 5 ANOVA summaries for Duroc progeny performances for ADG, FCR and BF

\begin{tabular}{|c|c|c|c|c|c|c|c|c|}
\hline \multirow{2}{*}{ Effect } & & \multirow{2}{*}{$\mathrm{N}$} & \multicolumn{2}{|c|}{ ADG $(g)$} & \multicolumn{2}{|c|}{$\mathrm{FCR}(\mathrm{kg})$} & \multicolumn{2}{|c|}{$\mathrm{BF}(\mathrm{mm})$} \\
\hline & & & LSMean & $\mathrm{N}$ & LSMean & $\mathrm{N}$ & LSMean & $\mathrm{N}$ \\
\hline \multirow[t]{4}{*}{ Country } & $\mathrm{CA}$ & 79 & $944.032^{a, b}$ & & & & $10.001^{a, b}$ & \\
\hline & F1-US & 1895 & $946.474^{a}$ & & $2.042^{b}$ & & $9.779^{a}$ & \\
\hline & USA & 339 & $964.299^{b}$ & & $1.903^{\mathrm{a}}$ & & $9.655^{\mathrm{a}}$ & \\
\hline & SA & 6576 & $949.565^{a}$ & & $2.048^{b}$ & & $9.900^{b}$ & \\
\hline \multirow[t]{3}{*}{ Farm } & $A$ & 1005 & $994.835^{c}$ & 8875 & $2.010^{b}$ & 955 & $9.713^{a}$ & 8875 \\
\hline & C & 7392 & $922.458^{a}$ & & $1.605^{a}$ & & $9.902^{b}$ & \\
\hline & $\mathrm{D}$ & 492 & $935.985^{b}$ & & $2.378^{c}$ & & $9.886^{a, b}$ & \\
\hline \multirow[t]{2}{*}{ Sex } & $\mathrm{F}$ & 4266 & $929.905^{a}$ & & $2.082^{b}$ & & $10.391^{b}$ & \\
\hline & $M$ & 4623 & $972.280^{b}$ & & $1.914^{\mathrm{a}}$ & & $9.277^{a}$ & \\
\hline
\end{tabular}

a, b, c, LSMeans with different superscripts in the same column for the same effect are significant

$\mathrm{N}=$ number of records, $A D G$ = average daily gain $(\mathrm{g}), \mathrm{FCR}=$ feed conversion ratio ( $\mathrm{kg}$ feed $/ \mathrm{kg}$ gain), BF = back fat thickness $(\mathrm{mm})$, LSMean = least square mean, CA = progeny sired by Canadian boars, F1-US = SA sired progeny with a USA grandsire, USA = progeny sired by USA boars, $S A=$ progeny sired by South African boars, $F=$ female, $M=$ male

In Table 6, the country performances showed differences for ADG, BF $(P<0.0001)$, and FCR $(P$ $<0.05)$. Although Canadian progeny performed worst $(P<0.05)$ in ADG, their BF performances were statistically not different from those of the progeny from other countries. No differences were observed for ADG between SA, F1-US and USA progeny, while the F1-US- and USA-sired progeny had the lowest FCR performances $(P<0.05)$. No differences were found between the lower USA and higher SA BF performances. Farm showed large differences $(P<0.0001)$ for all the three traits, although there were no differences between the performances of some farms.

Large differences were reported in sire country for ADG $(P<0.0001)$, BF $(P<0.0001)$ and FCR $(P$ $<0.05$ ) on-farm performances in the Large White breed (Table 7$)$. Although no differences were observed between SA and USA progeny performances for ADG, they were superior $(P<0.0001)$ to CA progeny performances. The USA sired progeny performances were superior in their FCR $(P<0.05)$ and $\mathrm{BF}(P$ 
$<0.0001)$ performances in comparison to CA and SA sired progeny. Farm performances differed $(P<0.0001)$ across the traits. The ADG performances of Farm $E$ and $A$ were highest $(P<0.0001)$. Farm $E$ and $G$ had a lower FCR $(P<0.0001)$ and the lowest BF $(P<0.05)$ performances. Large differences were noted between the sexes as male progeny performed better $(P<0.0001)$ than the female progeny for all the traits.

Across all the traits and breeds, sex was one of the largest contributors to variation. The smallest sex difference $(P<0.05)$ was observed in ADG for the Large White, where boars only gained $3.432 \mathrm{~g}$ per day, compared to the gilts. In all the other models, the sex differences were highly significant as the boars outperformed the gilts with a greater ADG, lower FCR and a lower BF.

Table 6 ANOVA summary for Landrace progeny performances for ADG, FCR and BF

\begin{tabular}{|c|c|c|c|c|c|c|c|c|}
\hline \multirow{2}{*}{ Effect } & & \multirow{2}{*}{$\mathrm{N}$} & \multicolumn{2}{|c|}{ ADG (g) } & \multicolumn{2}{|c|}{ FCR $(\mathrm{kg})$} & \multicolumn{2}{|c|}{$\mathrm{BF}(\mathrm{mm})$} \\
\hline & & & LSMean & $\mathrm{N}$ & LSMean & $\mathrm{N}$ & LSMean & $\mathrm{N}$ \\
\hline \multirow[t]{4}{*}{ Country } & $\mathrm{CA}$ & 119 & $856.705^{a}$ & \multirow{10}{*}{7306} & & \multirow{10}{*}{1289} & $10.498^{a, b}$ & \multirow{12}{*}{7306} \\
\hline & F1-US & 1304 & $898.096^{b}$ & & $2.287^{a, b}$ & & $10.383^{a}$ & \\
\hline & USA & 193 & $888.359^{b}$ & & $2.196^{a}$ & & $10.312^{a, b}$ & \\
\hline & SA & 5690 & $901.702^{b}$ & & $2.314^{b}$ & & $10.667^{b}$ & \\
\hline \multirow[t]{6}{*}{ Farm } & $A$ & 1918 & $909.876^{c}$ & & $2.124^{a}$ & & $10.125^{a}$ & \\
\hline & B & 315 & $887.869^{b}$ & & $2.257^{b}$ & & $9.907^{\mathrm{a}}$ & \\
\hline & $\mathrm{C}$ & 3142 & $857.825^{a}$ & & & & $11.519^{c}$ & \\
\hline & $D$ & 280 & $866.469^{a}$ & & $2.446^{c}$ & & $10.551^{b}$ & \\
\hline & $\mathrm{F}$ & 52 & $914.150^{c}$ & & & & $10.111^{\mathrm{a}, \mathrm{b}}$ & \\
\hline & $\mathrm{G}$ & 1599 & $882.105^{b}$ & & $2.234^{b}$ & & $10.576^{b}$ & \\
\hline \multirow[t]{2}{*}{ Sex } & $\mathrm{F}$ & 3987 & $864.659^{a}$ & & $2.379^{b}$ & & $10.820^{b}$ & \\
\hline & $M$ & 3319 & $908.325^{b}$ & & $2.152^{a}$ & & $10.109^{a}$ & \\
\hline
\end{tabular}

$a, b, c, d$, LSMeans with different superscripts in the same column for the same effect indicate significance

$\mathrm{N}=$ number of records, $\mathrm{ADG}=$ average daily gain $(\mathrm{g}), \mathrm{FCR}=$ feed conversion ratio $(\mathrm{kg}$ feed $/ \mathrm{kg}$ gain), BF = back fat thickness $(\mathrm{mm})$, LSMean = least square mean, CA = progeny sired by Canadian boars, F1-US = SA sired progeny with a USA grandsire, USA = progeny sired by USA boars, $S A=$ progeny sired by South African boars, $F=$ female, $M=$ male

\section{Discussion}

The global trend in pig production is towards increased efficiency and product quality. The response to selection is a direct result of the selection differential and the heritability of the trait being selected (Falconer \& Mackay, 1996); larger genetic improvement can therefore be expected in traits with higher heritability when selected parents are superior to the herd average. In South Africa, selection is directed towards an increase in ADG, reduced FCR and low BF, while maintaining a high NBA and 21DLWT (Dube et al., 2013; Visser \& Hofmeyer, 2014). Literature reported heritability estimates for production and carcass traits ranging from low to high; with BF having the highest heritability ranging from 0.42 to 0.72 (Suzuki et al., 2005), ADG has a moderate heritability with a range of 0.28 to 0.50 (Akanno et al., 2013; Clutter, 2011), while FCR has a low to moderate heritability ranging from 0.19 to 0.34 (Suzuki et al., 2005; Clutter, 2011; Akanno et al., 2013). Due to their moderate to high heritability and ease of measurement, these are important traits to consider when selecting boars, whether local or foreign.

In this study, 27334 progeny with on-farm performance records, across seven farms from 3010 sires, were evaluated. All the progeny were born on farms where both local- and foreign-sired progeny were raised during the same time period. Based on the average on-farm performances found in this study, the South African growth performances are on par with Canada and the USA. The SA progeny ended their growth test between 139 and 145 days with an ADG between 883 and $934 \mathrm{~g} /$ day, an FCR between 2.13 and $2.17(\mathrm{~kg}$ feed $/ \mathrm{kg}$ gain), and a BF thickness of 9.77 to $11.16 \mathrm{~mm}$ (as shown in Table 2). Average on-farm performances in Canada during 2015, as reported by the Canadian Centre for Swine Improvement (CCSI), were similar; the average age at $100 \mathrm{~kg}$ (for Duroc, Landrace and Large White) was 153 and 162 days for 
Table 7 ANOVA summary for Large White progeny performances for ADG, FCR and BF

\begin{tabular}{|c|c|c|c|c|c|c|c|c|}
\hline \multirow{2}{*}{ Effect } & & \multirow{2}{*}{$\mathrm{N}$} & \multicolumn{2}{|c|}{ ADG $(g)$} & \multicolumn{2}{|c|}{ FCR $(\mathrm{kg})$} & \multicolumn{2}{|c|}{$\mathrm{BF}(\mathrm{mm})$} \\
\hline & & & LSMean & $N$ & LSMean & $N$ & LSMean & $\mathrm{N}$ \\
\hline \multirow[t]{3}{*}{ Country } & $\mathrm{CA}$ & 91 & $833.918^{a}$ & & & & $10.757^{c}$ & \\
\hline & USA & 521 & $899.299^{b}$ & & $2.138^{a}$ & & $9.460^{a}$ & \\
\hline & SA & 10528 & $907.841^{b}$ & & $2.194^{b}$ & & $10.174^{b}$ & \\
\hline \multirow[t]{6}{*}{ Farm } & $A$ & 634 & $906.060^{d}$ & & $2.144^{b}$ & & $10.547^{b}$ & \\
\hline & C & 2161 & $853.588^{a}$ & & & & $11.090^{c}$ & \\
\hline & $\mathrm{D}$ & 498 & $868.207^{b, c}$ & 11139 & $2.398^{c}$ & 847 & $10.197^{b}$ & 11139 \\
\hline & $E$ & 137 & $910.174^{d}$ & & $1.953^{a}$ & & $9.468^{a}$ & \\
\hline & $\mathrm{F}$ & 5784 & $879.626^{c}$ & & $2.263^{b, c}$ & & $8.982^{a}$ & \\
\hline & $G$ & 1926 & $864.462^{b}$ & & $2.070^{a, b}$ & & $10.498^{b}$ & \\
\hline \multirow[t]{2}{*}{ Sex } & $\mathrm{F}$ & 5229 & $878.637^{a}$ & & $2.271^{b}$ & & $10.698^{b}$ & \\
\hline & $M$ & 5911 & $882.069^{b}$ & & $2.060^{a}$ & & $9.562^{a}$ & \\
\hline
\end{tabular}

a, b, c, d, LSMeans with different superscripts in the same column for the same effect indicate significance $\mathrm{N}=$ number of records, $\mathrm{ADG}=$ average daily gain $(\mathrm{g}), \mathrm{FCR}=$ feed conversion ratio $(\mathrm{kg}$ feed $/ \mathrm{kg}$ gain), BF = back fat thickness $(\mathrm{mm})$, LSMean = least square mean, CA = progeny sired by Canadian boars, USA = progeny sired by USA boars; $S A=$ progeny sired by South African boars, $F=$ female, $M=$ male

male and female pigs, respectively, while the average BF thickness was 10.4 and $10.2 \mathrm{~mm}$ for males and females, respectively (CCSI, 2015). Average USA on-farm performances, published annually by the National Pork Board, reported an average ADG of $839 \mathrm{~g} /$ day and a FCR of 2.70 (units feed/units gain) for conventional finisher productivity (National Pork Board, 2014). It must be kept in mind that the test period ends earlier in South Africa, where pigs are finished at 23 weeks with an average end weight of $90 \mathrm{~kg}$ (Visser, 2015), while performances reported in the USA had an average end weight of $125 \mathrm{~kg}$ at 27 weeks (National Pork Board, 2014). A similar trend was observed across the analyses as least square means from the ANOVAs indicated only small differences, albeit significant, in the ADG, FCR and BF performances among SA, USA and F1-US sired progeny. The small differences between countries can be explained by pig industries in respective countries selecting for similar traits as livestock production selects for an increased production efficiency and output, including an improved product quality (Thornton, 2010). In the pig industry, this equates to increased reproduction performance, increased feed efficiency and increased growth performance (Visser \& Hofmeyer, 2014). The performances of the CA sired progeny were either not significant (ADG and BF in Duroc, and BF in Landrace), or were found to be poorer (ADG in Landrace and Large White, and BF in Large White) in comparison to the progeny from other countries. Their poor performance can be explained by the small number of records available, accompanied by limited variation as indicated by the smaller standard deviations in comparison to the other progeny (Table 2). Differences observed can also be attributed to a genotype-country interaction due to large environmental differences between Canada, a cold temperate region, and South Africa, an arid and warm temperate region (Kottek et al., 2006; Peel et al., 2007).

Sex contributed a large portion of the variation, showing significant differences between the mean performances of male and female progeny across all breeds and traits, as males outperformed females for all traits. The findings in this study are in line with literature where entire males are known to be more efficient growers; having a higher lean to fat ratio and lower back fat thickness, lower feed intake, and a higher growth rate (Dunshea et al., 1993; Whittemore, 2006b; Lundström et al., 2009; Braña et al., 2013;) compared to gilts and castrates. Most studies investigating the effect of sex on growth and performance compare the performances of gilts and barrows or entire males and barrows (Bruininx et al., 2001; Latorre et al., 2004; Serrano et al., 2008; Braña et al., 2013). However, male piglets are rarely castrated in South Africa 
as they are marketed at 21 to 22 weeks of age, before the onset of puberty and the presence of a boar taint (Cilliers \& Schutte, 2014).

The differences among farms were highly significant for all the traits except BF in the Duroc. Farm differences include differences in nutrition, management practices and breeding objectives, as well as the limited influence of climate differences. Of the 3010 sires used in the study, only 30 were used on more than one farm, of which only six boars had progeny records on three or more farms. The farms are spread across South Africa, encompassing a range of bioregions and climates, although these have a limited effect as the pigs are reared in indoor housing systems. For this reason, the influence of year-season, which was highly significant across all breeds and traits, is also expected to be largely due to management, nutrition and breeding objectives changes, rather than climatic differences.

With the use of artificial insemination, breeders have the opportunity to utilise superior genetics from across the globe and ensure steady genetic progress is maintained. However, due to strict import requirements in South Africa, semen imports have been largely limited to sires from the USA and Canada (Visser, 2015). This has drastically reduced the available options for breeders in terms of sire choice. Although country differences ranged from significant to highly significant for all traits and breeds, the stepwise $R^{2}$ revealed that sire country contributed very little to the total variation found in on-farm progeny performances, while the role of farm, sex, and year-season contributed much larger portions to the variation. The relatively small variation contributed by country could be due to imported sires not being significantly superior to our local boars, or that these sires were not the top performers in their country of origin. Alternatively, it could indicate that sufficient genetic potential may already be available in South Africa.

\section{Conclusion}

The results indicate that the progeny tested in this study from local boars compared favourably with that produced from semen imported from Canada and the USA. Effects of management have been shown to contribute significantly to the differences observed. Breeders should be encouraged to select breeding stock based on accurate breeding values, keeping in mind the breeding objectives of the individual farm.

\section{Acknowledgements}

The authors acknowledge and express gratitude for the support of the South African Pork Producers Organisation.

\section{Authors' Contributions}

DAK performed the research and prepared the manuscript with input by HET and EVMK. All authors contributed to final editing and corrections.

\section{Conflict of Interest Declaration}

The authors acknowledge that there has been no conflict of interest in performing this research.

\section{References}

Akanno, E. C., Schenkel, F. S., Quinton, V. M., Friendship, R. M. \& Robinson, J. A. B., 2013. Meta-analysis of genetic parameter estimates for reproduction, growth and carcass traits of pigs in the tropics. Livest. Sci. 152, 101-113.

Braña, D. V., Rojo-Gómez, G. A., Ellis, M. \& Cuaron, J. A., 2013. Effect of gender (gilt and surgically and immunocastrated male) and ractopamine hydrochloride supplementation on growth performance, carcass, and pork quality characteristics of finishing pigs under commercial conditions. J. Anim. Sci. 91(12), 5894-5904.

Bruininx, E. M., van der Peet-Schwering, C. M., Schrama, J. W., Vereijken, P. F., Vesseur, P. C., Everts, H., Beynen, A. C., 2001. Individually measured feed intake characteristics and growth performance of group-housed weanling pigs : effects of sex, initial body weight, and body weight distribution within groups. J. Anim. Sci. 79, 301-308.

Buchanan, D. S. \& Stalder, K., 2011. Breeds of pigs. In M. F. Rothschild \& A. Ruvinsky (Eds.), The Genetics of the Pig (2nd ed., pp. 459460). Oxfordshire, UK: CAB International.

CCSI., 2012. Questions and Answers About Swine EBVs. Retrieved July 30, 2014, from https://www.ccsi.ca/main.cfm?target_page=geninfo

CCSI., $2015 . \quad$ Annual 2015.2 Available at: https://www.ccsi.ca/meetings/annual/Annualreport\%202015_FINAL.pdf.

Chesnais, J. P. \& Sullivan, B. P., 2002. Recent Developments in the Canadian Swine Improvement Program. In Proceedings of the National Swine Improvement Federation Conference and Annual Meeting. Nashville, Tennessee, USA. 
Cilliers, H. \& Schutte, A., 2014. Management aspects in your piggery. In D. Visser (Ed.), Modern Pig Production (1st ed., pp. 225-254). Krugersdorp, SA: Kejafa Knowledge Works.

Clutter, A. C., 2011. Genetics of performance traits. In M. F. Rothschild \& A. Ruvinsky (Eds.), The Genetics of the Pig (2nd ed., pp. 325-354). Oxfordshire, UK: CAB International.

Department of Agriculture Forestry and Fisheries., 2011. The National Agricultural Directory. South Africa: RainbowSA.

Department of Agriculture Forestry and Fisheries. (2014). Importation of live pigs, pig semen and embryos and certain porcine products into the Republic of South Africa, Animal Health Notification.

Dube, B., Mulugeta, S. D. \& Dzama, K., 2013. Genetic relationship between growth and carcass traits in Large White pigs. S. Afr.J. Anim Sci. 43(4), 482-492.

Dunshea, F. R., King, R. H., Campbell, R. G., Sainz, R. D. \& Kim, Y. S., 1993. Interrelationships Between Sex and Ractopamine on Protein and Lipid Deposition in Rapidly Growing Pig. J. Anim. Sci. 71(11), 2919-2930.

Falconer, D. S. \& Mackay, T. F. C., 1996. Introduction to quantitative genetics (4th ed.). New Jersey, USA: Prentice-Hall Inc.

Gerrits, R. J., Lunney, J. K., Johnson, L. A., Pursel, V. G., Kraeling, R. R., Rohrer, G. A. \& Dobrinsky, J. R., 2005. Perspectives for artificial insemination and genomics to improve global swine populations. Theriogenology, 63(2), 283-99.

Kirsten, J., Blignaut, C. \& Visser, D., 2009. Pork chains in South Africa. In J. Trienekens, B. Petersen, N. Wognum, \& D. Brinkmann (Eds.), European pork chains: diversity and quality challenges in consumerorientated production and distribution (pp. 233-243). The Netherlands: Wageningen Academic Publishers.

Kottek, M., Grieser, J., Beck, C., Rudolf, B. \& Rubel, F., 2006. World map of the Köppen-Geiger climate classification updated. Meteorologische Zeitschrift, 15(3), 259-263.

Latorre, M. ., Lázaro, R., Valencia, D. G., Medel, P. \& Mateos, G. G., 2004. The effects of gender and slaughter weight on the growth performance, carcass traits, and meat quality characteristics of heavy pigs. J. AnimSci. 82, 526-533.

Lundström, K., Matthews, K. R. \& Haugen, J.E., 2009. Pig meat quality from entire males. Animal: An International J. Anim. Biosci. 3(11), 1497-507.

National Pork Board., 2014. 2009-2014 Productivity Analysis. Available at: http://www.pork.org/wpcontent/uploads/2010/04/pork-industry-productivity-analysis-2015-summary.pdf.

NSR., 2013. STAGES Genetic Evaluation Summary. Retrieved July 27, 2013, from https://mail.nationalswine.com:8443/newstages/

Peel, M. C., Finlayson, B. L. \& Mcmahon, T. A., 2007. Updated world map of the Köppen-Geiger climate classification. Hydrology Earth Systems Science Discussion, 4, 439-473.

Robinson, J. A. B. \& Buhr, M. M., 2005. Impact of genetic selection on management of boar replacement. Theriogenology, 63, 668-678.

SAS., 2014. SAS Enterprise Guide. Retrieved June 4, 2014, from http://www.sas.com/en_us/software/enterprise-guide.html

Serrano, M. P., Valencia, D. G., Nieto, M., Lázaro, R. \& Mateos, G. G., 2008. Influence of sex and terminal sire line on performance and carcass and meat quality of Iberian pigs reared under intensive production systems. Meat Sci. 78(4), 420-428.

Streicher, S., 2013. Personal Communication. CEO of South African Pork Producers Organisation. simon@sapork.com.

Suzuki, K., Kadowaki, H., Shibata, T., Uchida, H. \& Nishida, A., 2005. Selection for daily gain, loin-eye area, backfat thickness and intramuscular fat based on desired gains over seven generations of Duroc pigs. Livest.Prod. Sci. 97(2-3), 193-202.

Thornton, P. K., 2010. Livestock production: recent trends, future prospects. Philosophical Transactions of the Royal Society B: Biological Sciences, 365(1554), 2853-2867.

Visser, D., 2015. Personal Communication. Pig breeding and genetics advisor. visserdanie84@gmail.com.

Visser, D., Foss, S. \& Labuscagne, A., 2014. Pig Reproduction. In D. Visser (Ed.), Modern Pig Production (pp. 105-125). Krugersdorp, SA: Kejafa Knowledge Works.

Visser, D. \& Hofmeyer, J., 2014. Breeding and Genetics. In D. Visser (Ed.), Modern Pig Production (First, pp. 71-103). Krugersdorp, SA: Kejafa Knowledge Works.

Whittemore, C., 2006a. Development and Improvement of Pigs by Genetic Selection. In I. Kyriazakis \& C. T. Whittemore (Eds.), Whittemore's Science and Practice of Pig Production (3rd ed., pp. 184-262). Oxford, UK: Blackwell Publishing Ltd.

Whittemore, C., 2006b. Growth and body composition changes in pigs. In I. Kyriazakis \& C. Whittemore (Eds.), Whittemore's Science and Practice of Pig Production (3rd ed., pp. 65-103). Oxford, UK. 